\title{
Alkynes and Azides, Not Just for Click Reactions
}

\author{
I. F. Dempsey Hyatt, Maria Elena Meza-Aviña, Mitchell P. Croatt* \\ I. F. Dempsey Hyatt, Maria Elena Meza-Aviña, and Mitchell P. Croatt. “Alkynes and Azides: Not Just for Click Reactions.” Synlett \\ 2012, 23, 2869-2874. \\ Made available courtesy of Georg Thieme Verlag: https://www.thieme-connect.com/ejournals/abstract/10.1055/s-0032-1317545
}

\begin{abstract}
***Reprinted with permission. No further reproduction is authorized without written permission from Georg Thieme Verlag. This version of the document is not the version of record. Figures and/or pictures may be missing from this format of the document. $* * *$
\end{abstract}

Department of Chemistry and Biochemistry, University of North Carolina at Greensboro, 435 Sullivan Science Building, PO Box 6170 , Greensboro, NC 27402, USA

Fax:(336)334-5402

mpcroatt@uncg.edu

Received: The date will be inserted once the manuscript is accepted.

\begin{abstract}
We recently reported two unexplored reactivities of alkynes and azides. The first method reacts nucleophilic alkynes and electrophilic azides to synthesize sulfonylsubstituted 1,5-disubstituted-1,2,3-triazoles. The second method reacts electrophilic alkynes with nucleophilic azides to form alkynyl-azides that immediately extrude dinitrogen to form cyanocarbenes which were trapped by $\mathrm{O}-\mathrm{H}$ insertion, sulfoxide complexation, and cyclopropanation. The design and discovery of these reactions, along with key observations, is discussed herein.
\end{abstract}

Key words: Azides, alkynes, carbenes, umpolung, heterocycles

The toolbox of a synthetic chemist is full of many different and individually useful reactions that can be used to construct a targeted molecule. These tools range from the screw driver of classic reactions like the Diels-Alder reaction to the utility knife of the Sharpless asymmetric epoxidation. Just like there are many different types of tools, reactions often include selected reactive intermediates such as radicals, cations, and anions. One of the most overlooked, yet powerful reactive intermediates to be used as a means to adding complexity to a molecule is the carbene. Few reactive intermediates can claim direct utilization of transformations such as $\mathrm{C}-\mathrm{H}, \mathrm{O}-\mathrm{H}, \mathrm{N}-\mathrm{H}$, and $\mathrm{Si}-\mathrm{H}$ insertions, sulfoxide complexation, addition to double bonds, addition to triple bonds, rearrangements, and reacting as a nucleophile, electrophile, and diradical. ${ }^{1}$ With so many possible reactions, the carbene is the hammer in our toolbox. Fortunately, substitution of the carbene modulates its reactivity from that of a jack hammer to a sledge hammer or even a claw hammer. This means that controlling what the carbene interacts with and how it reacts requires judicious choices prior to carbene formation.

Our original idea to work in this area spawned from the work of the Lee group ${ }^{1 \mathrm{c}}$ where they utilized the metallotropic bond shift of propargylic carbenes (conversion of $\mathbf{3 a}$ to $\mathbf{3 b}$ ) and trapped them via subsequent metathesis reactions (Scheme 1). It was envisioned that the analogous nitrogen version, an alkynyl nitrene (5a), would be in equilibrium with a cyanocarbene (5b). It was also hypothesized that alkynyl-nitrene 5a could be accessed from an alkynylazide (4). ${ }^{2}$ Although alkynyl-azides had not been reported in the literature, we felt that this could be due to the potential facile extrusion of $\mathrm{N}_{2}$ and the incredibly high reactivity of the resultant alkynylnitrene or cyanocarbene.

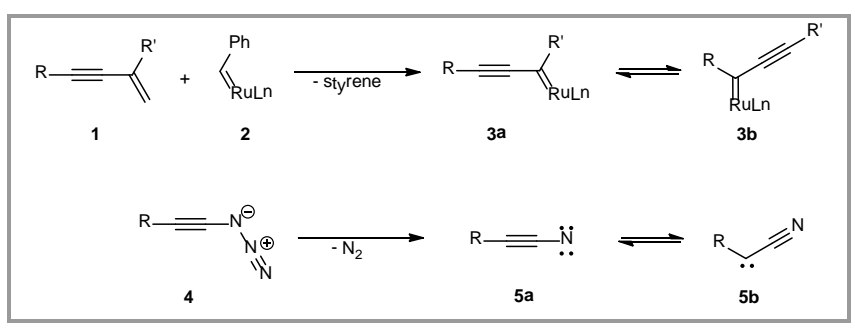

Scheme 1 Propargylic carbene rearrangements.

Feeling confident in our reaction concept, a search of the chemical literature quickly revealed what often occurs in science; researchers had already begun work in the area. The first reported attempt to isolate an alkynyl-azide was in 1910 by Forster and Newman via base-induced elimination in aqueous solution of 1azido-1,2-dibromoethane but only 2bromoacetaldehyde was isolated. ${ }^{4}$ Subsequent reports of theoretical ${ }^{5}$ and experimental findings ${ }^{2 e, 6}$ were published of efforts to access cyanocarbenes from alkynes and azides. The most fruitful of these involved a collaboration between Auer and Banert where they predicted in 2007 that cyanocarbenes could form from alkynyl-azides. $^{2 b}$ In 2010, the Banert group was able to isolate products that result from trapping of a proposed cyanocarbene after its formation from an assumed alkynyl-azide. ${ }^{1 \mathrm{~d}}$ These reactions were performed with sodium azide and several chloro-alkynes. Not discouraged by the originality of our idea being thwarted, we decided to see if we could improve upon Banert's work by experimenting with different precursors to the alkynyl-azide and subsequent cyanocarbene.

Towards the goal of forming cyanocarbenes from nucleophilic alkynes and electrophilic azides, we first 
examined the reaction of $n$-pentylacetylide with sulfonyl azides. ${ }^{7}$ This led us to the formation of 1,5disubstituted-1,2,3-triazoles (7) as the primary products (Scheme 2). This reaction has been previously reported, ${ }^{2 \mathrm{~d}}$ however, the yields were often poor and the scope was never explored. Importantly, the products we were synthesizing were different from the 1,4-disubstituted-1,2,3-triazoles synthesized using the more classic conditions, CuI and 2,6-lutidine. Specifically, the processes to synthesize 1,5disubstituted-1,2,3-triazoles utilize either a ruthenium catalyst $^{9 \mathrm{a}}$ or acetylides, ${ }^{9 \mathrm{~b}, 9 \mathrm{c}}$ neither of which has been shown to be form 1,5-disubstituted sulfonyl-triazoles. ${ }^{9}$ Conditions using copper salts and amine bases with sulfonyl-azides has received much attention since the initially formed 1,4-disubstituted products can undergo further reactions such as to make amides and imides. $^{10}$ Indeed, the 1,4-disubstituted sulfonyltriazoles are rarely stable to the reaction conditions and often react further. For example, there are reports of 1,4-disubstituted sulfonyl-triazoles reacting with amine bases to form the respective 2,4-disubstituted1,2,3-triazoles. ${ }^{11}$ It therefore appeared that the reaction we had come across (Scheme 2) had the opportunity to fill a hole in the types of triazoles that can be easily accessed.

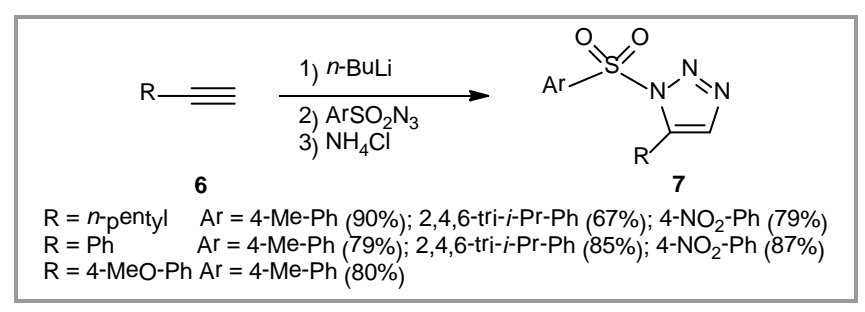

Scheme 2 Synthesis of 1,5-Substituted Triazoles.

In order to optimize this reaction, we tried different bases, solvents, temperatures and ratios of reagents, finding that the more efficient reaction conditions were when a slight excess of the alkyne was used and the reaction was run cold in THF. Deviation from these conditions often resulted in either a lower yield or decrease in the selectivity for the 1,5-substituted product. A series of alkynes and sulfonyl azides were used giving moderate to good yields (Scheme 2).

Consideration of the mechanism illustrates that we were not far off from our quest to synthesize alkynylazides (Scheme 3). If triazene anion $\mathbf{8 a}$ had eliminated the arylsulfinate anion, the goal would have been accomplished. As it turns out, cyclization in a 5-endo-dig fashion was lower in energy to form triazole anion 8b. Although our mechanistic understanding has not heretofore led to an alternative to the cyclization, it was realized that the reaction of the triazole anion (8b) with other electrophiles could lead to structures with increased molecular complexity. When electrophiles other than Brønsted acids were used to quench the triazole anion, trisubstituted triazoles (11) with a sulfonyl group, an alkyl group and a ketone, ester, silyl, or alkyl group were formed when reacted with an acid chloride, chloroformate, silyl chloride, or alkyl halide, respectively (Scheme 4). The products were typically obtained in moderate yields, however, the less reactive electrophiles resulted in lower yields, often due to quenching from exogenous water.

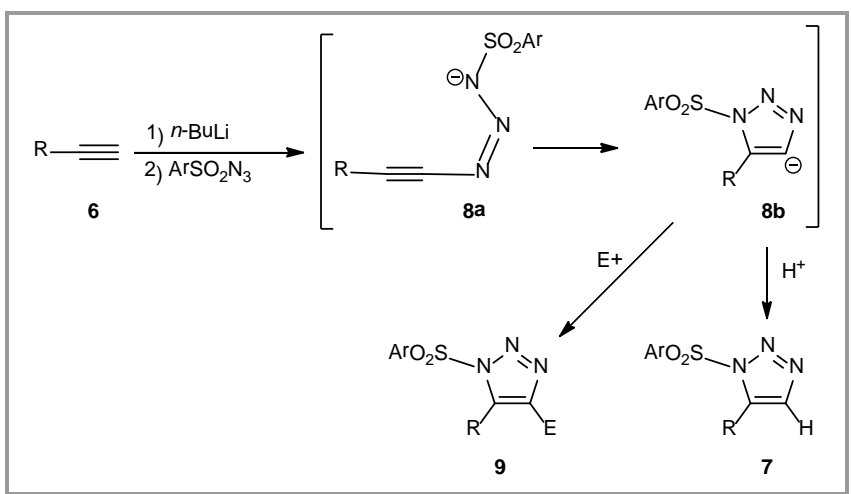

Scheme 3 Proposed mechanism.

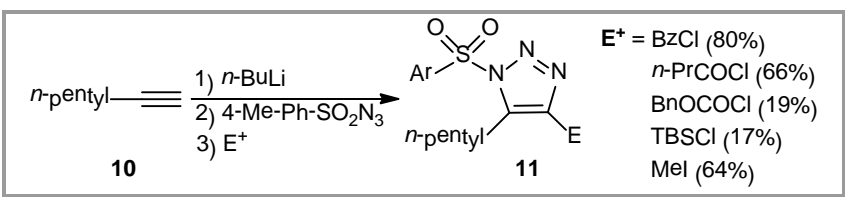

Scheme 4 Synthesis of 1,4,5-Trisubstituted -triazoles.

During the purification of the disubstituted triazoles (7), we observed isomerization and decomposition if the silica gel chromatography was not performed quickly. Luckily, we were able to crystallize the products from ethyl acetate and hexane for purification. As a major confirmation of our findings, we were able to obtain suitable crystals to perform Xray analysis and unequivocally assign our products as 1,5-disubstituted sufonyl-triazoles. Unexpectedly, crystals isolated and spectroscopically identified as 1,5 -sulfonyl triazoles were found to isomerize to 1,4 sulfonyl triazoles if stored in solid state for periods longer than a week (Figure 1). To investigate this isomerization, a sample was kept in an NMR tube in $\mathrm{CDCl}_{3}$ at room temperature and compared with a crystallized sample. Surprisingly, the sample in $\mathrm{CDCl}_{3}$ had no observed isomerization while the solids significantly isomerized within 28 days. We hypothesize that this reaction potentially occurs in the crystal lattice due to a) the relatively short distance, $5.39 \AA$, between the nitrogen atom at the 3-position of one triazole and the sulfur atom on a neighboring triazole, b) the orientation of this nitrogen and the sulfur atom, and c) the experimental evidence that the crystalized product isomerizes. 


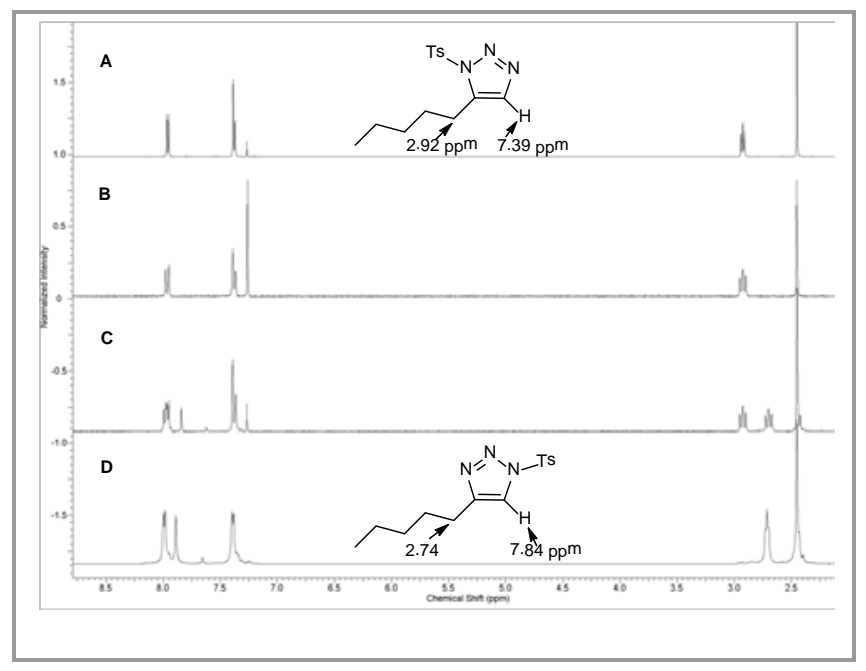

Figure 1 A) Day 1. B) Day 28 in solution at rt. C) Day 28 solid kept at $-20{ }^{\circ} \mathrm{C}$. D) Day 42 solid kept at $-20{ }^{\circ} \mathrm{C}$.

The described reactions of acetylides and sulfonylazides combine commercially available starting materials to synthesize 1,5-disubstituted-1,2,3triazoles in an efficient way. ${ }^{7}$ It was also possible to achieve the formation of trisubstituted triazoles in a completely regioselective fashion. Currently, we are working to study the reactivity of the 1,5-disubstituted triazoles under thermal and transition metal catalyzed conditions. Initial results indicate the extrusion of dinitrogen and potentially carbene or radical intermediates.

The discovery of a route to 1,5-sulfonyl triazoles was an unexpected success, however, we decided to return to the initial goal of accessing cyanocarbenes from alkynyl-azides. For our second generation attempt, we used an umpolung approach implementing hypervalent iodonium alkynyl triflates (HIATs) as electrophilic alkynes to be reacted with nucleophilic azide sources. ${ }^{12}$ The use of HIATs stemmed from the work of Stang et al., ${ }^{13}$ Zhdankin et al., ${ }^{14}$ and Zefirov et $a .^{15}$ in that they all clearly demonstrated the synthesis, isolation, and reactivity of these highly electrophilic, yet moderately stable species.

In 1988, it was reported that when hypervalent iodonium phenylethynyl tosylate (12) was reacted with $\mathrm{NaN}_{3}$ in $\mathrm{MeOH}$ at $-70{ }^{\circ} \mathrm{C}$ and then warmed to ambient temperature, a $3 \%$ yield of an vinylidene carbene O-H insertion product (14) and a 23\% yield of a substituted azirine (15) was observed (Scheme 5). ${ }^{2 \mathrm{~g}}$ We questioned whether the structural assignment of the azirine was correct and instead hypothesized that perhaps phenyl cyanocarbene had formed and reacted with methanol in an $\mathrm{O}-\mathrm{H}$ insertion reaction to yield cyanoether 16 (Scheme 7) ${ }^{16}$ The ${ }^{13} \mathrm{C}$ NMR of the reported azirine product contained a peak at 116.89 ppm which was assumed to be part of the benzene ring, however, we envisioned that this was actually the carbon of the nitrile. The most downfield-shifted carbon reported was $133.16 \mathrm{ppm}$, but this still is unlikely for the $\mathrm{C}=\mathrm{N}$ of the azirine.

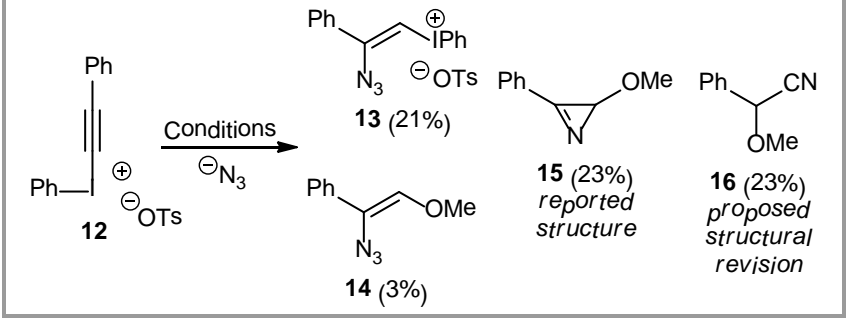

Scheme 5 Previously reported products from a reaction of iodonium alkynes and azides. ${ }^{2 \mathrm{~g}}$

Further scrutiny of the literature was highly rewarding since 2-methoxy-2-phenylacetonitrile (16) is a known compound $^{17}$ and the characterization data matched that of the reported azirine (15). ${ }^{2 \mathrm{~g}}$ The apparent misinterpretation of data was a minor point in a brief communication so we anticipated that this had gone unnoticed. This seems to be the case, and it fortunately led us down the path to successfully form cyanocarbenes from azides and alkynes.

Our proposed mechanism of substitution involves the addition of an azide source to the $\beta$-carbon of the HIAT (17), thereby forming the iodo-ylide (19) which decomposes to iodobenzene and the vinylidene carbene (20). ${ }^{18}$ Vinylidene carbene 20 can then undergo a 1,2-rearrangement via migration of either the azide or the R-group to afford alkynyl-azide $\mathbf{2 1}$. This alkynyl-azide has previously been shown to extrude dinitrogen to form cyanocarbene $\mathbf{1 8}$ which can react with a substrate. ${ }^{1 \mathrm{~d}, 2 \mathrm{2b}, 19}$ We envisioned that vinylazide 20 could also eliminate dinitrogen with concomitant rearrangement to directly form cyanocarbene 18. Either of these mechanistic possibilities could form desired cyanocarbene $\mathbf{1 8}$.

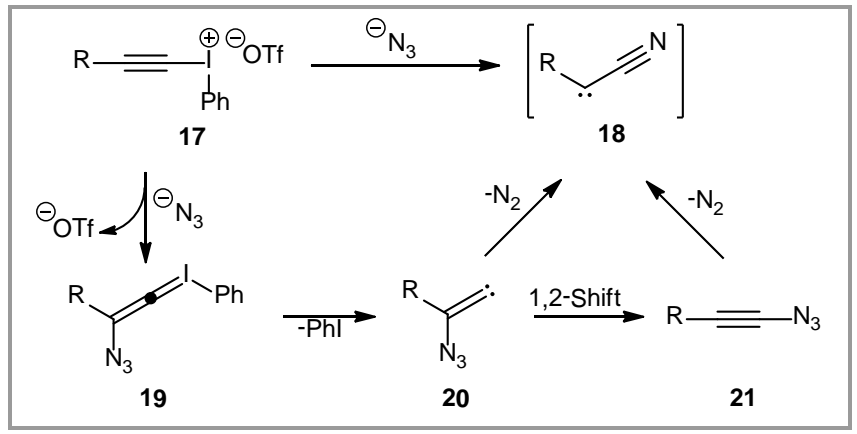

Scheme 6 Formation of cyanocarbenes from HIATs.

With the knowledge that we were about to create the hammer of reactive intermediates, we decided to first soften the blow by trapping the cyanocarbene with solvent (Scheme 7). Several HIATs have been synthesized by our group but in our recently published article $^{12}$ we chose to focus on two specific HIATs that show the viability and variability with both aryl and alkyl groups. 


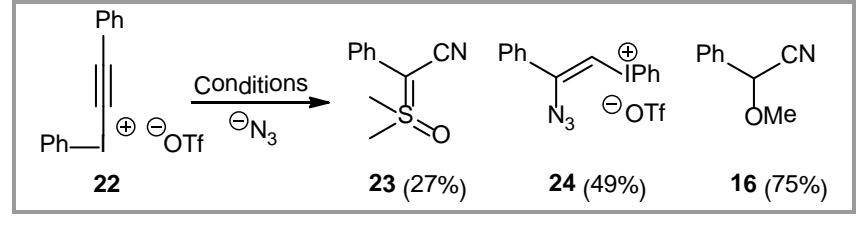

Scheme 7 Reactions with phenyl-HIAT and either $\mathrm{NaN}_{3}$ or $\mathrm{NBu}_{4} \mathrm{~N}_{3}$ with the solvent as DMSO, DCM/ $\mathrm{H}_{2} \mathrm{O}, \mathrm{MeOH}$, respectively. Highest yields are shown from a series of reaction conditions.

The reaction with $\mathrm{MeOH}$ lead to products 24 and $\mathbf{1 6}$ and the yields and ratios of products varied upon changing temperature, molar equivalency, and azide sources. Lower temperatures did not favor the extrusion of iodobenzene and instead preferred the faster reaction of direct protonation of iodo-ylide 19 to form iodonium alkenyl triflate 24. By raising the temperature to $25^{\circ} \mathrm{C}$, the selectivity of the reaction could be altered and, gratifyingly, a $75 \%$ yield of a product resulting from a cyanocarbene could be isolated. This represents the highest yield for the $\mathrm{O}-\mathrm{H}$ insertion reaction ${ }^{16}$ of a cyano-carbene formed from an alkyne and an azide and is the same product as was misinterpreted as an azirine in a previous publication (vide supra). $^{2 \mathrm{~g}}$

Interestingly, the $n$-pentyl-HIAT (25) had less of a propensity to rearrange and form the cyanocarbene than did the phenyl-HIAT (Scheme 8). The $n$-pentylHIAT preferred to react as the vinylidene carbene intermediate (20) rather than rearrange and extrude $\mathrm{N}_{2}$. This information implies that the rearrangement is facilitated by the phenyl group electronics with either the azide or the phenyl group migrating to form the intermediate alkynyl azide (21).

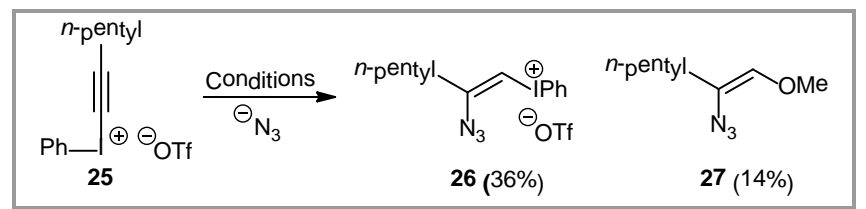

Scheme 8 Reaction with $n$-pentyl-HIAT and either $\mathrm{NaN}_{3}$ or $\mathrm{NBu}_{4} \mathrm{~N}_{3}$ with the solvent as $\mathrm{DCM} / \mathrm{H}_{2} \mathrm{O}$, or $\mathrm{MeOH}$.

Although the reaction with solvent is of limited practicality, it was crucial in the determination of how the HIAT could be used to obtain the cyanocarbene. With our preliminary experimental knowledge we were able to then turn our attention to other reactions and found immediate success with cyclopropanations (Scheme 9). The cyclopropanation reaction series consisted of either running the reaction in minimal DCM or solventless. The yields for reactions without solvent increased by about $20 \%$ compared to when DCM is used as the solvent. This is due to the carbene intermediates reacting with DCM, as determined by running reactions in DCM and $\mathrm{d}_{2}$-DCM. Unfortunately, these byproducts were never isolable due to volatility. It should also be noted that the $n$ pentyl-HIAT appears to undergo cyclopropanation with allylbenzene similar to the Ph-HIAT, but the product was not stable to silica gel and thus definitive characterization was unobtainable.

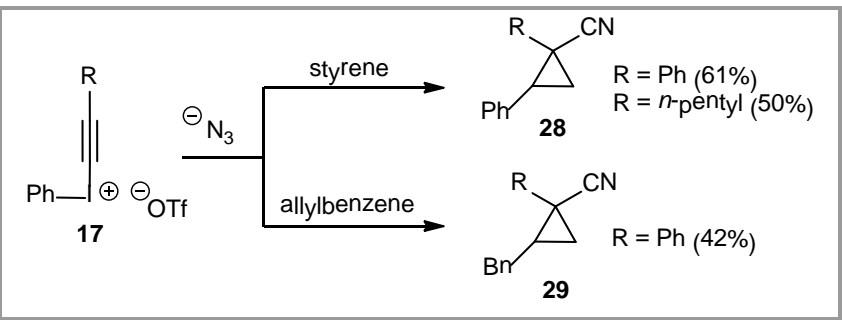

Scheme 9 Reaction used $\mathrm{NBu}_{4} \mathrm{~N}_{3}$ with the solvent as DCM or solventless. Highest yields for the solventless reaction are shown.

The cyclopropanation reactions with the $n$-pentylHIAT rearrange and extrude dinitrogen to form the cyanocarbene before undergoing the cyclopropanation whereas previously the $n$-pentyl-HIAT was reacting as the vinylidene carbene (compare Scheme 8 versus Scheme 9). It is hypothesized that the alkenes, styrene and allyl benzene, are less reactive than methanol and therefore the rate of intramolecular rearrangement and formation of the cyanocarbene out-competes reaction with the alkenes. Further investigation into the factors which influence vinylidene carbene versus cyanocarbene formation are warranted as the results could add significant steps to controlling the yield and thus availability of this reaction to the synthesis community.

In order to gain more insight into what factors influence cyanocarbene formation, some exploratory reactions were run (Scheme 10). The deuterium exchange demonstrates that the vinyl proton of the iodonium-alkene (26) is abnormally acidic, presumably due to formation of the iodo-ylide. Under basic conditions, the $\mathrm{O}-\mathrm{H}$ insertion products ${ }^{16}$ of vinylidene carbenes (27 and 31) were formed from both the phenyl- and n-pentyl-iodonium alkenes. Only the Ph-HIAT precursor was able to form the product resulting from a cyanocarbene (16). This result supports the hypothesis that the conversion of vinylidene carbene $\mathbf{2 0}$ to cyanocarbene $\mathbf{1 8}$ can be interrupted with a sufficiently reactive trapping agent. When treating iodonium alkene 24 with a nonnucleophilic base in the presence of styrene, the cyanocarbene was formed and cyclopropanation was observed in a modest yield. 


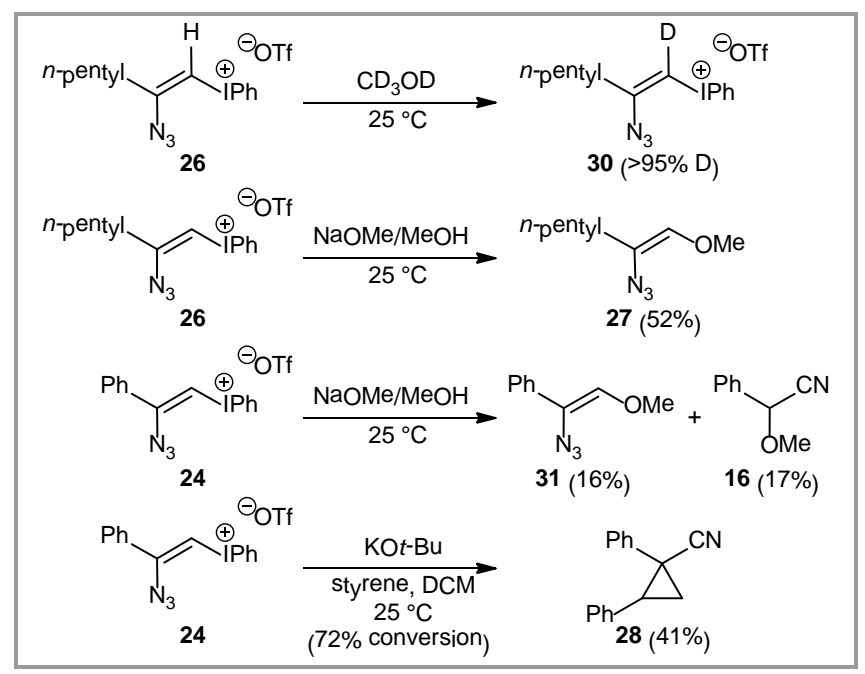

Scheme 10 Deprotonation of alkenyl iodoniums.

Contemporaneous and independent of the research of our group, ${ }^{12}$ the Banert group was able to use conditions similar to ours to isolate and characterize an alkynyl azide, one hundred and two years after the first reported efforts to synthesize them. ${ }^{19}$ The alkynyl azide, azido-acetylene, was isolated by reacting ethynyl iodonium salts with hexadecyltributylphosphonium azide in DCM at -40 ${ }^{\circ} \mathrm{C}$. Under vacuum, highly volatile azidoacetylene and the solvent were recondensed into another flask cooled by liquid nitrogen. This led to a solution of azidoacetylene (yield ca. 40\%, ${ }^{1} \mathrm{H}$ NMR), which contained only traces of iodobenzene. It is noted for safety that during recondensation an explosion of azidoacetylene is possible. Banert et al. was able to

\section{Acknowledgment}

Funding for this project from the American Chemical Society Petroleum Research Fund (52488-DNI1) and the University of North Carolina at Greensboro is gratefully acknowledged.

\section{References}

(1) (a) Kim, M.; Miller, R. L.; Lee, D. J. Am. Chem. Soc. 2005, 127, 12818. (b) Cho, E. J.; Lee, D. Org. Lett. 2008, 10, 257. (c) Yun, S. Y.; Wang, K.; Kim, M.; Lee, D. J. Am. Chem. Soc. 2010, 132, 8840. (d) Banert, K.; Hagedorn, M.; Wutke, J.; Ecorchard, P.; Schaarschmidt, D.; Lang, H. Chem. Commun. 2010, 4058.

(2) (a) D'yachkova, S. G.; Nikitina, E. A.; Gusarova, N. K.; Albanov, A. I.; Trofimov, B. A. Russ. J. Gen. Chem. 2003, 73, 782. (b) Prochnow, E.; Auer, A. A.; Banert, K. J. Phys. Chem. A 2007, 111, 9945. (c) Helwig, R.; Hanack, M. Chem. Ber. Recl. 1985, 118, 1008. (d) Boyer, J. H.; Selvaraj, R. J. Am. Chem. Soc. 1969, 91, 6122. (e) Tanaka, R.; Yamabe, K. J. Chem. Soc. 1983, 329. (f) Boyer, J. H.; Mack, C. H.; Goebel, N.; Morgan, L. R.; J. Org. Chem. 1958, 23, 1051. (g) Kitamura, T.; Stang, P. J. Tetrahedron Lett. 1988, 29, 1887. (h) Banert, K. in Organic Azides-Syntheses and Applications (Eds.: Bräse, S.; Banert, K.), Wiley, Chichester, 2010, pp. $115-166$.

(3) (a) Zhao, Z.-X.; Zhang, H.-X.; Sun, C.-C. J. Phys. Chem. A 2008, 112, 12125. (b) Gronert, S.; Keeffe, J. R.; More O’Ferrall, R. A. J. Am. Chem. Soc. 2011, 133, characterize the azidoacetylene by ${ }^{1} \mathrm{H},{ }^{13} \mathrm{C},{ }^{15} \mathrm{~N}$, and IR at low temperatures. Additionally, they performed high-level calculations, working again with Auer et al., of the azido-acetylene and found that the calculated structure correlated closely with their spectroscopic information.

As we have shown in this SYNPACTS article, despite the wealth of reactions of azides and alkynes reported in recent years, including "Click Chemistry" 20 and other processes like the "Banert Cascade" ${ }^{21}$ there were still fundamentally new methods to have them react. These reactions make two new tools available for the construction of molecules. Our approaches for accessing cyanocarbenes included reacting nucleophilic acetylides with electrophilic azides and the umpolung method of reacting electrophilic iodonium-alkynes with nucleophilic azides. The electrophilic azide reactions formed 1,2,3-triazole products with the uncommon 1,5-positioning of the substituents. ${ }^{7}$ The electrophilic alkyne reactions were able to traverse alkynyl-azides en route to cyanocarbenes. $^{12}$ The reactions using HIATs are the highest yielding for formation of cyanocarbenes from alkynes and azides. Empirical data from our group, along with recent results from Banert and Auer, ${ }^{19}$ suggest that formation of an iodo-ylide (19) and azidesubstituted vinylidene carbene (20) occurs prior to formation of the azido-alkyne (21) and desired cyanocarbene (18). Further investigation into these reaction mechanisms and practical uses are currently underway.

3381. (c) Maier, G.; Reisenauer, H. P.; Rademacher, K.; Chem. Eur. J. 1998, 4, 1957. (d) Josef, K. Chem. Phys. Lett. 2005, 403, 146.

(4) Forster, M. O.; Newman, S. H. J. Chem. Soc. 1910, 97, 2570.

(5) Kim, K. S.; Schaefer, H. F.; Radom, L.; Pople, J. A.; Binkley, J. S. J. Am. Chem. Soc. 1983, 105, 4148.

(6) (a) Hui, H. K. W.; Shechter, H. Tetrahedron Lett. 1982, 23, 5115. (b) Lodaya, J. S.; Koser, G. F. J. Org. Chem. 1990, 55, 1513. (c) Ochiai, M.; Kunishima, M.; Fuji, K.; Nagao, Y. J. Org. Chem. 1988, 53, 6144. (d) Koumbis, A.; Kyzas, C.; Savva, A.; Varvoglis, A. Molecules 2005, 10,1340 .

(7) Meza-Aviña, M. E.; Patel, M. K.; Lee, C. B.; Dietz, T. J.; Croatt, M. P. Org. Lett, 2011, 13, 2984.

(8) (a)Yoo, E. J.; Ahlquist, M.; Kim. S. H.; Bae,I.; Fokin, V. V.; Sharpless, K. B.; Chang, S. Angew. Chem., Int. Ed. 2007, 46, 1730. (b) Wang, F.; Fu, H.; Jiang, Y.; Zhao, Y. Adv. Synth. Catal. 2008, 350, 1830.

(9) (a) Boren, B. C.; Narayan, S.; Rasmussen, L. K.; Zhang, L.; Zhao, H.; Lin. Z.; Jia, G.; Fokin, V. V. J. Am. Chem. Soc. 2008, 130, 8923. (b) Krasiński, A.; Fokin, V. V.; Sharpless, K. B. Org. Lett. 2004, 6, 1237. (c) Kwok, S. W.; Fotsing, J. R.; Fraser, R. J.; Rodionov, V. O.; Fokin, V.V. Org. Lett. 2010, 12, 4217.

(10) (a) Cassidy, M. P.; Raushel, J.; Fokin, V. V. Angew. Chem., Int. Ed. 2006, 45, 3154. (b) Yoo, E. J.; Ahlquist, M.; Bae, I.; Sharpless, K. B.; Fokin, V. V.; Chang S. J. Org. Chem. 2008, 73, 5520. (c) Yoo, E. J.; Chang, S. Org. Lett. 2008, 10, 1163. 
(11) Yamaguchi, M.; Miura, T.; Murakami, M. Heterocycles 2010, 80, 177.

(12) Hyatt, I. F. D.; Croatt, M. P. Angew. Chem., Int. Ed. 2012, 51, 7511.

(13) (a) Bachi, M. D.; Bar-Ner, N.; Crittell, C. M.; Stang, P. J.; Williamson, B. L. J. Org. Chem. 1991, 56, 3912. (b) Stang, P. J. Angew. Chem. 1992, 104, 281. (c) Stang, P. J.; Surber, B. W.; Chen, Z. C.; Roberts, K. A.; Anderson, A. G. J. Am. Chem. Soc. 1987, 109, 228. (d) Stang, P. J.; Crittell, C. M. Organometallics 1990, 9, 3191. (e) Williamson, B. L.; Stang, P. J.; Arif, A. M. J. Am. Chem. Soc. 1993, 115, 2590.

(14) (a) Zhdankin, V. V.; Scheuller, M. C.; Stang, P. J.; Tetrahedron Lett. 1993, 34, 6853. (b) Zhdankin, V. V.; Stang, P. J. Chem. Rev. 2008, 108, 5299.

(15) Zefirov, N. S.; Zhdankin, V. V.; Dan’kov, Y. V.; Koz'min, A. S. J. Org. Chem. USSR (Engl. Trans.) 1984, 20, 401.

(16) The "O-H insertion" is presumably not a concerted O-H insertion due to the strength of $\mathrm{O}-\mathrm{H}$ bonds but instead more likely involves the addition of the oxygen of methanol to the carbene followed by subsequent proton transfer.

(17) Reich, H. J.; Biddle, M. M.; Edmonston, R. J. J. Org. Chem. 2005, 70, 3375.

(18) Kitamura, T.; Zheng, L.; Taniguchi, H.; Sakurai, M.; Tanaka, R. Tetrahedron Lett. 1993, 34, 4055.

(19) Banert, K.; Arnold, R.; Hagedorn, M.; Thoss, P.; Auer, A. A. Angew. Chem. Int. Ed. 2012, 51, 7515.

(20) Kolb, H. C.; Finn, M. G.; Sharpless, K. B. Angew. Chem. Int. Ed. 2001, 40, 2004.

(21) Loren, J. C.; Sharpless, K. B. Synthesis 2005, 9, 1514. 


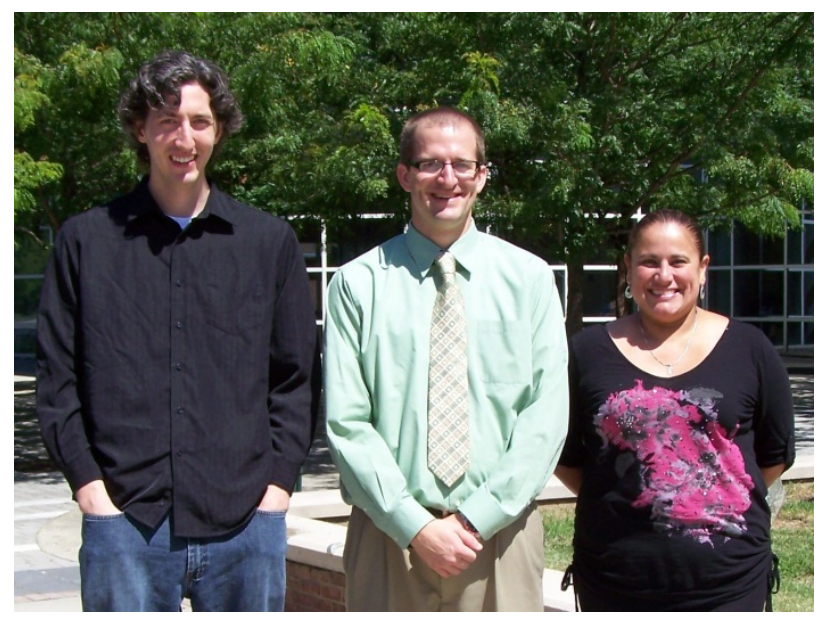

Ivan Fabe Dempsey Hyatt (left) grew up in Staley, North Carolina. He earned his BS in Chemistry and BA in Mathematics from East Carolina University and his PhD in Chemistry from the University of Florida for the synthetic and computational study of nonadentate lanthanide complexes. He is currently a postdoctoral fellow at the University of North Carolina at Greensboro. Mitchell P. Croatt (center) grew up in New Prague, Minnesota. Mitch earned his BS in Chemistry from the University of Minnesota, Twin Cities in 2002 after doing undergraduate research in the group of George A. O'Doherty and then his PhD from Stanford University in 2007 under the guidance of Paul A. Wender. After postdoctoral research with Erick M. Carreira at ETH-Zurich, he started his academic career as an Assistant

Professor at the University of North Carolina at Greensboro in 2010. Maria Elena Meza-Aviña (right) grew up and earned her undergraduate degree in Industrial Chemistry at Tampico Tamaulipas Mexico from Universidad del Noreste in 1993 and her $\mathrm{PhD}$ in Chemistry from Universidad Autonoma del Estado de Morelos, Cuernavaca, Morelos, Mexico in 2005. In 2006, she began her postdoctoral research at UHN-Toronto, ON, Canada under Prof. Lakshmi P. Kotra until 2010 when she joined the Croatt group at the University of North Carolina at Greensboro.

\section{Alkynes and Azides, Not Just for Click Reactions}

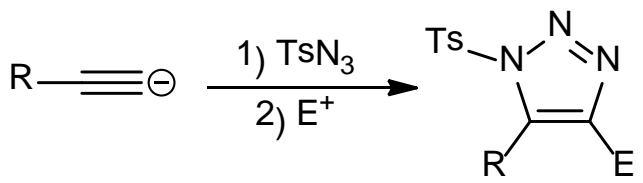

\section{Different reactivity} for umpolung reactions<smiles>[R]C#C[Ge]([O-])([O-])c1ccccc1</smiles><smiles>[R]C#C[C@H](C)N</smiles><smiles>[R]C=C(C)CCC</smiles> 